\title{
Funções: construindo conceitos a partir da análise gráfica
}

\section{Functions: constructing concepts from graphical analysis}

\author{
Diego Souza da Silva \\ Universidade Federal de Santa Maria - UFSM, Santa Maria, RS \\ diego.edy@hotmail.com \\ João Roberto Lazzarin \\ Universidade Federal de Santa Maria - UFSM, Santa Maria, RS \\ joaolazzarin@gmail.com
}

Resumo: O objetivo deste trabalho foi verificar como uma prática pedagógica baseada na construção e interpretação de gráficos durante o processo de ensino de funções facilita a aprendizagem e provê de significado o conceito de função. Trata-se de uma pesquisa qualitativa, realizada por meio de oficinas sobre funções, aplicada a 12 alunos do $3^{\circ}$ ano do Ensino Médio de uma escola estadual do Rio Grande do Sul. Na sequência didática desenvolvida empregou-se, em cada etapa, a abordagem visual dos diversos conceitos e definições relativas a funções, por meio dos esboços de gráficos e de construções dinâmicas, realizadas com o software livre GeoGebra. Também foram levantadas algumas das dificuldades encontradas no processo de ensino-aprendizagem de Matemática, e uma sequência de atividades que explora os principais conceitos inerentes a funções lineares, quadráticas, exponenciais e logarítmicas foi proposta, a partir da modelagem e resolução de problemas reais.

Palavras-chave: ensino-aprendizagem de funções; análise gráfica; geoGebra.

Abstract: The objective of this work was to verify how a pedagogical practice based on the construction and interpretation of graphs during the teaching process of functions facilitates the learning and provides meaning to the concept of function. It is a qualitative research carried out through workshops about functions, applied to 12 students of the 3rd year of High School, of a public school of Rio Grande do Sul. In the didactic sequence developed, at each stage, the visual approach of the various concepts and definitions related to functions was used, through graphic sketches and dynamic constructions, performed with GeoGebra free software. Some of the difficulties encountered in the teaching-learning process of Mathematics were also raised, and a sequence of activities that explores the main concepts inherent to linear, quadratic, exponential and logarithmic functions was proposed, from the modeling and resolution of real problems.

Key words: teaching-learning functions; graphical analysis; geoGebra.

\section{Introdução}

A Matemática faz parte da evolução humana e é utilizada nas mais diversas áreas de atuação do homem, ou mesmo nas atividades mais simples do cotidiano, inserindo-se de 
Revista Ciências Exatas e Naturais, Vol.20, nº.1, Jan/Jun, 2018

forma definitiva na vida das pessoas, tornando sua presença na educação escolar cada vez mais necessária para a evolução científica e produção de novos saberes.

De acordo com [1], na escola, em função da maneira como muitas vezes é abordada, como uma ciência fragmentada e isolada, a Matemática se distancia de seus significados e objetivos previstos para o Ensino Fundamental e Médio. Para mudar essa realidade se faz necessária uma reflexão profunda por parte dos educadores matemáticos no sentido de reverter essa apatia metodológica que se constata no ensino dessa ciência.

No entanto, percebe-se, no contato com artigos publicados em revistas da área, nos trabalhos apresentados em congressos e em publicações atuais, que o ensino da Matemática passa por um processo de reformulação. Novas metodologias de ensino são exigidas para dar conta de uma visão diferenciada sobre o papel do educador, cuja principal missão será desenvolver novas posturas pedagógicas que, em vez da transferência de conteúdos prontos, acentuam a interação do aluno com o objeto de estudo.

Especificamente, ao se tratar do estudo de funções matemáticas, sabe-se que o conceito de função e os desenvolvimentos relacionados a ele são bases para a abordagem dos mais diversos tipos de problemas científicos e estão presentes no estudo de diversos outros conteúdos em matemática, do nível básico ao superior, vários trabalhos tais como[2,3], retratam esse assunto. A aprendizagem desse objeto matemático é essencial para o aluno de nível médio, uma vez que o principal objetivo nesta fase é o desenvolvimento de sua capacidade em descrever e estudar fenômenos da realidade, de modo a se tornar capaz de entendêlos, construir diagnósticos e previsões tornando-se apto a intervir propositivamente em seu cotidiano.

Porém cabe salientar que, as dificuldades na aprendizagem de funções não se apresentam de forma superficial, ao contrário, são por vezes inerentes à álgebra, à interpretação e a outros conceitos subsidiários. As trocas conceituais ou conceitos mal construídos, as falhas nas representações e respectivas transformações e os significados contraditórios atribuídos a conceitos ao tratar das funções matemáticas, revelam a necessidade de ações que vão além da mera transmissão de saberes fragmentados e dissociados da realidade dos educandos.

Desta forma, o objetivo geral deste trabalho foi verificar como uma prática pedagógica baseada na construção e interpretação de gráficos durante o processo de ensino de funções facilita a aprendizagem e mune de significado tal conceito. Na próxima seção apresenta-se uma síntese dos fundamentos conceituais que embasaram esta pesquisa. Posteriormente, relatase e discute-se os resultados obtidos por meio da aplicação e avaliação de uma sequência didática, aplicada a uma turma de $3^{\circ}$ ano do Ensino Médio, que, durante a introdução e o desenvolvimento do estudo de funções, deu o enfoque principal à abordagem visual que se pode fazer dos diversos conceitos e definições relativas às funções, possibilitada por meio dos esboços de gráficos e de construções dinâmicas realizadas com o software GeoGebra, junto a atividades que visaram a resolução de problemas reais.

\section{Fundamentos Conceituais}

O Ensino Médio tem reunido alguns dos piores indicadores da educação brasileira. É nessa etapa da educação básica que se concentram as maiores taxas de abandono escolar e também as notas mais baixas no Índice de Desenvolvimento da Educação Básica (IDEB), índice que mede a qualidade de nossas escolas. Quanto à Matemática, dados apresentados pelo Instituto Nacional de Estudos e Pesquisas Educacionais Anísio Teixeira (INEP) [4], revelam que as proficiências médias em matemática caíram no Ensino Médio pela segunda 
Diego Souza da Silva e João Roberto Lazzarin

vez consecutiva, sendo que resultados anteriores apontaram que apenas 10,3\% dos alunos brasileiros terminam o Ensino Médio sabendo o que deveriam em matemática, ou seja, quase $90 \%$ dos alunos não aprendem o esperado. Taís índices vêm a confirmar o descrito por [1]: "A matemática, tão presente em nossa vida cotidiana por meio de objetos técnicos, para muitos de nós é, no entanto, cada vez mais invisível e estranha".

Entretanto, as Orientações Curriculares para o Ensino Médio (OCEM) [5] estabelecem que ao final do Ensino Médio os alunos saibam usar a Matemática para resolver problemas práticos do cotidiano e modelar fenômenos, percebendo sua importância no desenvolvimento científico, tecnológico e em diversas atividades humanas. Estes objetivos destinados ao Ensino Médio mostram que o ensino de matemática não pode ser transformado em um fim em si mesmo.

Neste contexto, surgem tendências na área da Educação Matemática, que envolvem diferentes abordagens consideradas importantes quando aplicadas ao processo de ensinoaprendizagem como a Modelagem Matemática, a Resolução de Problemas e o Uso de Tecnologias.

A Modelagem Matemática é um processo pelo qual se quer analisar algum fato da realidade, sendo que para isso temos que levantar dados sobre o objeto estudado, formulando hipóteses e criando modelos a fim de encontrarmos soluções aproximadas do fato em questão, ou seja, analisar através de esquemas matemáticos. "A modelagem consiste, essencialmente, na arte de transformar situações da realidade em problemas matemáticos cujas soluções devem ser interpretadas na linguagem usual" [6].

A Resolução de Problemas é uma das concepções mais difundidas sobre o ensino de matemática. De acordo com [7] pode-se dizer que um problema "[...] é um obstáculo a ser superado, algo a ser resolvido e que exige o pensar consciente do indivíduo para solucioná-lo". Logo, toda situação que exija um processo de reflexão para solucioná-la pode ser caracterizada como um problema. Os autores [7] e [9] determinam algumas etapas para a resolução de problemas: compreendê-lo, através da leitura e interpretação cuidadosa; elaborar um plano de resolução, formulando hipóteses e fazendo tentativas; executar o plano, pondo em prática todas as estratégias pensadas; verificar os resultados, repassando as etapas da estratégia proposta e comparando com maneiras diferentes de resolução e, por fim, elaborar a resposta à pergunta do problema.

O Uso de Tecnologias no ensino-aprendizagem de matemática está se tornando uma tendência pedagógica muito difundida no âmbito educacional. Os Parâmetros Curriculares Nacionais (PCN) [10] trazem o recurso às tecnologias como um dos caminhos para "fazer Matemática" na sala de aula. E mais adiante, apontam o computador como o instrumento mais relevante no impacto das tecnologias sobre o ambiente educacional.

Tendo como objetivo o desenvolvimento da capacidade dos estudantes de descrever e estudar fenômenos da realidade, de modo a se tornarem capazes de entendê-los, construir previsões, e, assim tornarem-se aptos a intervir na realidade, a aprendizagem de funções é de fundamental importância e deve acontecer a partir da contextualização e da interdisciplinaridade, permitindo conexões entre diversos conceitos e diferentes formas de pensamento matemático. Segundo [5], deve-se explorar o caráter integrador que este tema possui, a partir de seus exemplos de aplicações com os diferentes modelos que devem ser objeto de estudo na escola - modelos linear, quadrático e exponencial.

A introdução da ideia de função é um pré-requisito para se fazer ciência, pois nela estão embutidas as noções de determinação, eventualmente expressando causalidade, previsibilidade e regularidade dos fenômenos, e a partir dela se tem condições de entender a maneira como se dão as relações de dependência entre diferentes grandezas. Para Carneiro [3] as 
Revista Ciências Exatas e Naturais, Vol.20 , nº.1, Jan/Jun, 2018

relações de dependência funcional entre variáveis, a interpretação e análise de gráficos, pontos críticos, modelagem, noções de limites e taxas de variação são conceitos que podem aparecer naturalmente ainda no Ensino Médio. Para tal, é essencial trabalhar com situações problemas reais, o que motiva o estudante a interessar-se por aquilo que está aprendendo e mostra que a matemática é útil na vida cotidiana.

Acredita-se que quanto maior for a possibilidade de articulação entre diferentes registros de representação do mesmo objeto matemático, maior será a possibilidade de apreensão desse objeto. A conceituação e a aquisição de conhecimentos ocorrem somente quando o aluno consegue transitar naturalmente por diferentes registros. Sendo assim, durante o ensino de funções deve-se oportunizar que os alunos estabeleçam relações entre suas diferentes representações, ajustando seus conhecimentos sobre funções a fim de construir um modelo para interpretação e investigação em Matemática. De acordo com [10], não basta buscarmos novos métodos de ensino, "se os conceitos são apresentados de forma fragmentada, mesmo que de forma completa e aprofundada, nada garante que o aluno estabeleça alguma significação para as ideias isoladas e desconectadas umas das outras".

A fim de propiciar aos alunos transitar entre as diferentes formas de representar funções e torná-los aptos a lidar com o conceito de função em diversas situações, entende-se que é necessária a utilização de gráficos, não apenas como suporte, mas como base para uma aprendizagem significativa de funções. Pois, a expressão através de gráficos é utilizada na representação de dados em diversos conteúdos e é a forma mais adequada para apresentar informações sobre linearidade, intervalos de crescimento e decrescimento, máximos e mínimos, taxas de variação, regularidade, continuidade. Os gráficos expressam uma visão geral e completa das funções e suas características.

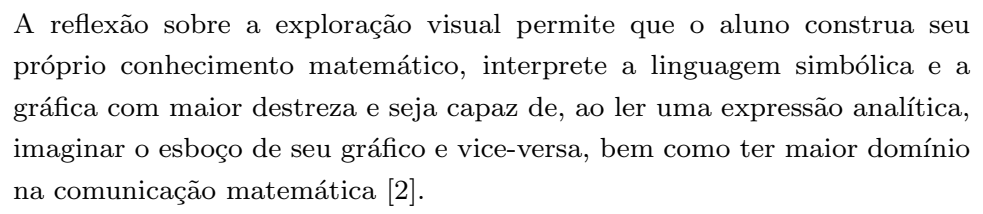

As OCEM [5] atentam para o fato de que: "a elaboração de um gráfico por meio da simples transcrição de dados tomados em uma tabela numérica não permite avançar na compreensão do comportamento das funções". O estudo de gráficos na representação e significação do conceito de função deve ser realizado de forma diferenciada a fim de que os alunos possam visualizar padrões algébricos. "É importante destacar o significado da representação gráfica das funções, quando alteramos seus parâmetros, ou seja, identificar os movimentos realizados pelo gráfico de uma função quando alteramos seus coeficientes" [5].

Desse modo, sugere-se que durante o estudo de funções, seja dada ênfase à representação gráfica, nos passos iniciais, bem como no desenvolvimento do conceito de função e na compreensão de suas características, usufruindo assim do caráter integrador que o tema possui.

\section{Resultados e Discussão}

Os resultados aqui expostos se referem ao relato e a análise de uma sequência didática sobre funções aplicada, em uma escola estadual do município de Canela - RS, com 12 alunos do $3^{\circ}$ ano do Ensino Médio que não tiveram contato com este conteúdo matemático nos anos anteriores devido à falta de professores. Durante a aplicação desta proposta, necessitou-se da sala de informática por 15 períodos de 45 minutos cada e do laboratório de ciências por 
Diego Souza da Silva e João Roberto Lazzarin

2 períodos. Na sala de informática foram utilizados 13 notebooks, um para cada aluno e um para o professor. Cada notebook possuía o software GeoGebra ${ }^{1}$ previamente instalado. O professor ainda fez uso de um projetor e de uma lousa, a fim de orientar as atividades realizadas pelos alunos e apresentar os comandos do software a serem utilizados, visto que alguns alunos ainda não conheciam o GeoGebra. Na sequência são relatadas, de forma resumida, algumas das atividades desenvolvidas com os alunos durante a aplicação de quatro oficinas, assim como os resultados obtidos na aprendizagem das funções.

\subsection{Oficina 1 - Funções e Conceitos}

A primeira oficina, com duração de 6 períodos, tratou de função e conceitos subjacentes e teve por objetivo oportunizar a aprendizagem da definição de função, assim como levar os alunos a intuir ideias inerentes ao tema por meio da abordagem visual, da exposição à diversos gráficos e relações.

Inicialmente, foram apresentados aos alunos alguns gráficos de situações reais que representam funções, seguidos de questionamentos, para que percebessem as ideias de variação e dependência entre grandezas e a importância do conteúdo na previsão de fenômenos. Tais recursos detiveram a atenção dos alunos, podendo ainda mostrar que a Matemática está presente em seu cotidiano, que ela é útil no dia a dia e que também é uma forma de linguagem. Desta forma, os estudantes tiveram o contato inicial com o conceito de função informalmente, estabelecendo relações com a terminologia relacionada a esse assunto.

Posteriormente, os alunos foram apresentados ao software GeoGebra, com o qual estudaram a definição formal de função por meio de uma construção dinâmica, realizada por eles e orientada pelo professor. Esta atividade teve por objetivo facilitar a compreensão da definição de função, domínio, contradomínio e imagem, a partir da análise de gráficos e do estabelecimento de relações entre gráficos, expressões analíticas e definições formais. No GeoGebra, os alunos representaram a relação $f: R \Rightarrow R, f(x)=0,5 x^{5}+3 x^{2}-2 x$, criaram um ponto $A$ sobre o eixo $x$, uma reta $r$ perpendicular ao eixo das abscissas que passa por $A$ e sua intersecção com a curva representativa da expressão anteriormente digitada na entrada de comandos do software (Figura 1).

Ao mover o ponto $A$ sobre o eixo $x$ os alunos puderam compreender que estavam percorrendo valores pertencentes ao domínio da função $f$ e ainda observaram suas respectivas imagens descritas pela ordenada do ponto $B$, criado pela intersecção do gráfico de $f$ com a reta $r$. De posse da definição formal de função, conseguiram, através da interpretação gráfica, relacionar o domínio e o contradomínio da função $f$ com os números reais representados, respectivamente, no eixo $x$ e no eixo $y$. Perceberam ainda, que $r$ sempre intersecta o gráfico de $f$ num único ponto, verificando assim a definição de função. Os alunos repetiram a mesma atividade com outras relações que expressam, ou não, funções, sempre justificando o porquê de uma determinada relação não representar uma função.

Com o uso de gráficos os estudantes compreenderam os conceitos de função par e função ímpar de uma forma descontraída, analisaram a simetria de gráficos e aplicaram-na para caracterizar funções. Para o estudo da função par e da função ímpar os alunos receberam um arquivo que trazia na janela gráfica do GeoGebra 5 pontos fixos $(B, C, D, E, F)$ e 6 pontos móveis $(A, B 1, C 1, D 1, E 1, F 1)$ todos ligados por segmentos de reta a fim de representarem uma função como esboçado na Figura 2. Pondo em prática a definição de função par e função ímpar moveram os pontos necessários até obter a representação adequada ao gráfico

\footnotetext{
${ }^{1} 1$-GeoGebra - Software gratuito de matemática dinâmica, no qual pode-se ver ao mesmo tempo as representações gráficas e algébricas de um mesmo objeto matemático. Disponível em https://www.geogebra.org/.
} 
Revista Ciências Exatas e Naturais, Vol.20 , nº.1, Jan/Jun, 2018

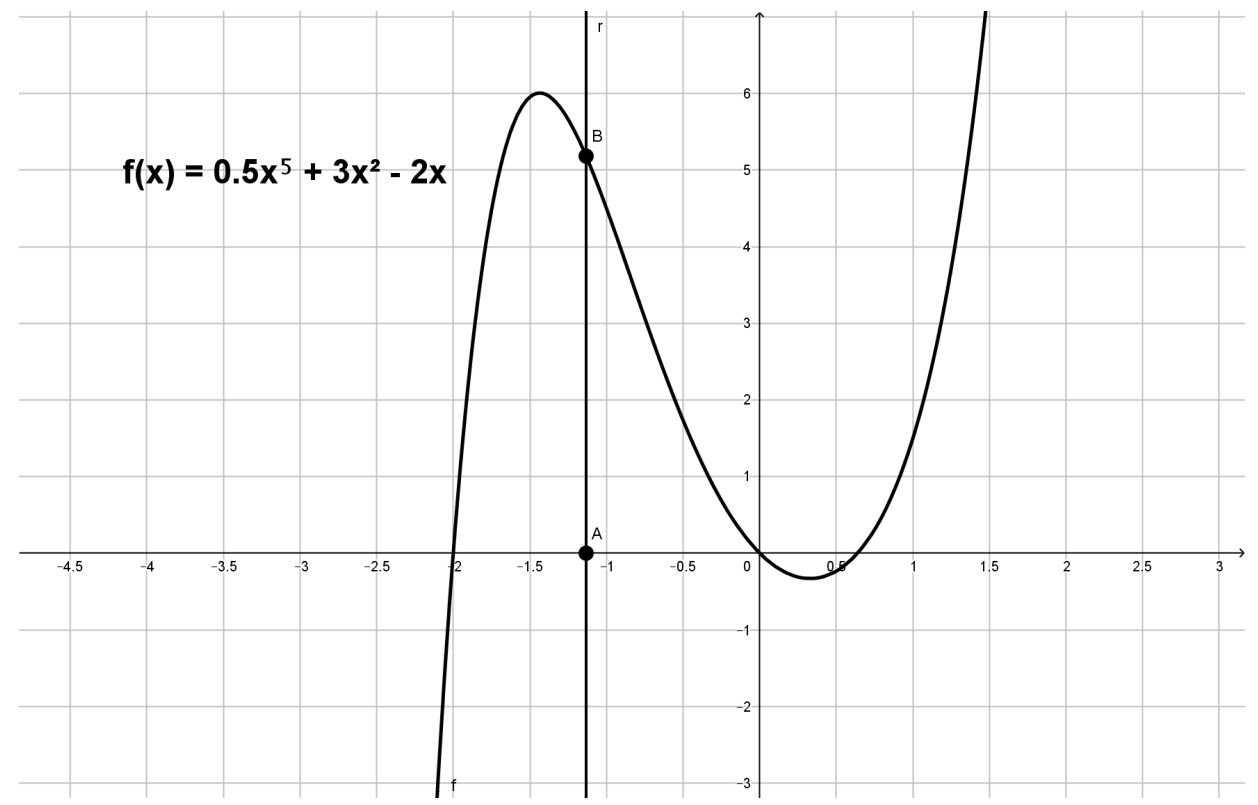

Figura 1. Gráfico e análise da relação $f: R \Rightarrow R, f(x)=0,5 x^{5}+3 x^{2}-2 x$.

de uma função par e posteriormente de uma função ímpar. Feito isso analisaram a simetria existente nos gráficos.

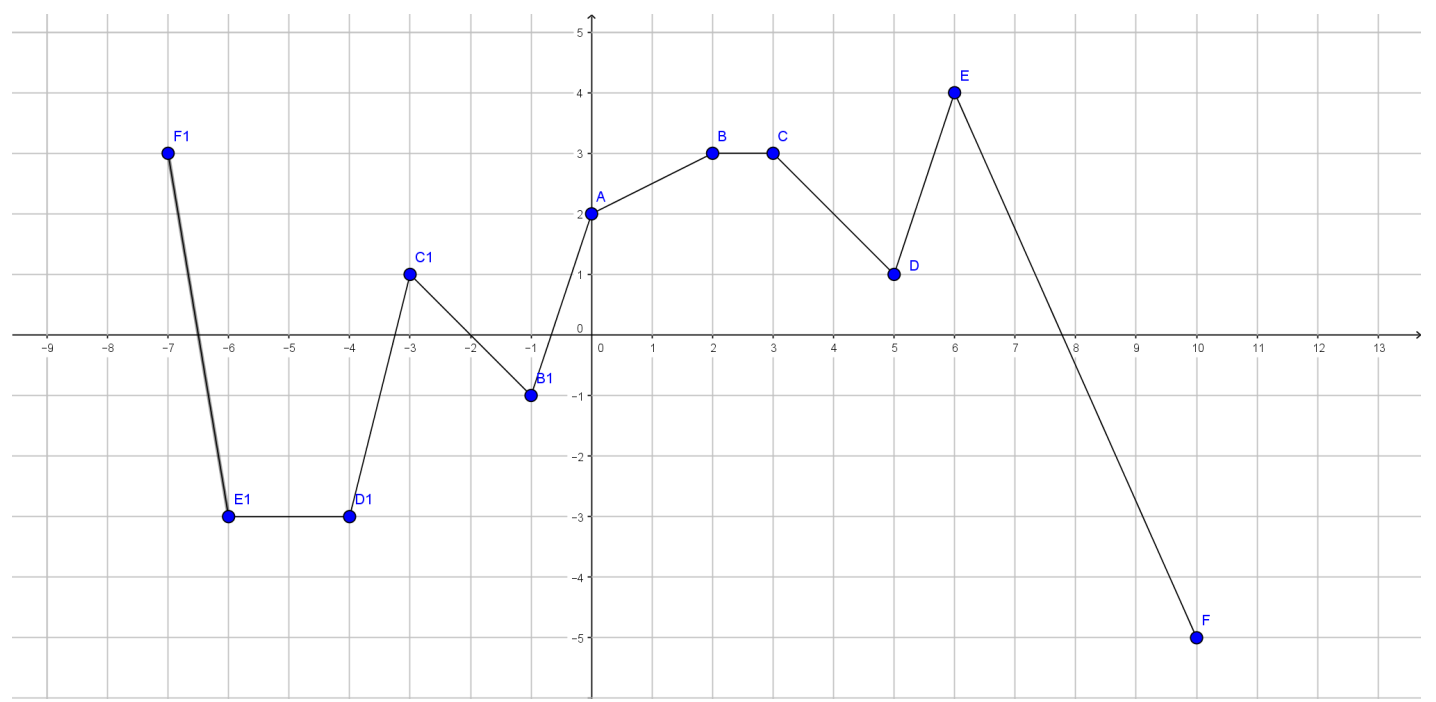

Figura 2. Atividade sobre função par e função ímpar.

Mediante atividades de interpretação gráfica estudou-se, ainda nessa oficina, as definições de função crescente e função decrescente. Durante a análise das atividades realizadas pelos alunos foi possível perceber que, apesar de inúmeras dificuldades de interpretação e prin- 
Diego Souza da Silva e João Roberto Lazzarin

cipalmente de expressão, os alunos mostraram interesse e motivação para abordar o tema funções utilizando o GeoGebra. Pode-se concluir que a abordagem usada na proposta apresentada leva os estudantes a serem cada vez mais autônomos no processo de aprendizagem, fazendo do professor um mediador e facilitador deste processo, ao escolher as atividades e intervir quando necessário para a construção de novos saberes.

\subsection{Oficina 2 - Função Afim}

Nesta oficina, durante 5 períodos, teve-se como objetivo iniciar o estudo da função afim e seus casos particulares, através de uma abordagem prática desenvolvida com base nos pressupostos teóricos sobre modelagem matemática. Também buscou-se investigar, as contribuições trazidas pelo uso de gráficos para a criação e validação de um modelo e a valia do software GeoGebra para compreender as características da função afim. Portanto, esperavase que durante esta oficina os estudantes construíssem o conceito de função afim, estabelecessem relações entre as diferentes formas de expressar uma função e ainda, aprendessem a fazer uso desses conhecimentos para resolver situações problemas.

Primeiramente desenvolveu-se uma atividade experimental no laboratório de ciências, na qual os alunos, inicialmente, coletaram uma quantidade $x$ de água com a proveta graduada, quantidade esta escolhida por eles, despejaram a água num frasco cilíndrico reto, mediram a altura que o nível da água atingiu no frasco e tomaram nota dos dados em mililitros (ml) e milímetros $(\mathrm{mm})$. Depois despejaram, sobre a quantidade já existente no frasco, novas quantidades de água, mediram a altura dos respectivos níveis de água e anotaram os dados: quantidade de água no frasco $(\mathrm{ml})$ e altura da água no frasco $(\mathrm{mm})$. Posteriormente, fizeram o esboço dos dados no plano cartesiano.

A partir da análise dos dados representados no plano cartesiano os estudantes visualizaram a relação de dependência entre as variáveis dependente e independente envolvidas no experimento, criando um modelo, representado por uma função afim, para estudar a situação proposta. Durante esta atividade notou-se que o principal benefício trazido pela metodologia utilizada foi a motivação dos alunos em participar da construção do experimento e do modelo matemático desenvolvido para estudá-lo. A quantidade de água não ter sido previamente determinada pelo professor foi um fator que contribuiu para que os alunos pudessem escolher as variáveis, dependente e independente, corretamente e também, para que conseguissem perceber a continuidade da função.

Ainda que de difícil construção para os alunos, o esboço do gráfico, feito a partir dos dados inicialmente levantados, serviu de suporte para a construção e validação do modelo utilizado para estudar o experimento realizado, mostrando que a construção e análise de gráficos pode auxiliar para que a atividade de modelagem matemática aconteça de forma significativa.

Construir o experimento com as próprias mãos, facilitou para que os alunos descrevessem a situação estudada como uma função e compreendessem a relação entre as variáveis sem o auxílio do professor. No decorrer da atividade o professor pode ainda, observar as principais dificuldades trazidas pelos alunos a fim de intervir e utilizar novas estratégias para saná-las, dentre estas dificuldades salienta-se à construção do gráfico de uma função afim.

Na segunda etapa da oficina, os alunos construíram, no GeoGebra, uma reta dinâmica a partir de controles deslizantes $a$ e $b$, que representam os parâmetros da função, cuja lei de associação foi digitada na entrada de comandos do software. Tendo construído a reta, os educandos puderam modificar os valores dos parâmetros e da função e observar as mudanças ocasionadas no seu gráfico. Analisando o gráfico, perceberam que a reta (gráfico da função 
Revista Ciências Exatas e Naturais, Vol.20 , nº.1, Jan/Jun, 2018

afim) intersecta o eixo $x$ no ponto de ordenada, e que o parâmetro $a$ tem relação com a inclinação da reta, que quando $a>0$ a função é crescente, se $a<0$ a função é decrescente e para $a=0$ a função é constante.

Visando estabelecer o conceito de taxa de variação e uma técnica para obter o parâmetro $a$ a partir do gráfico de uma função afim, os alunos criaram sobre a reta dinâmica anteriormente construída dois pontos $A$ e $B$, e posteriormente desenharam um triângulo retângulo $A B C$ de hipotenusa $A B$. Determinaram as medidas dos catetos do triângulo $A B C$, usando a calculadora obtiveram o valor da tangente do ângulo BÂC e observaram sua relação com o parâmetro $a$ da função $f(x)=a \cdot x+b$ (Figura 3). A partir desta atividade mostrou-se que a taxa de variação da função afim é dada por $a=\frac{f\left(x_{2}\right)-f\left(x_{1}\right)}{x_{2}-x_{1}}$, para $x_{2} \neq x_{1}$, e que a mesma é sempre constante para cada função afim. Assim, os alunos construíram os conhecimentos necessários para transitar entre a representação gráfica e algébrica de uma função afim, como lhes foi proposto em algumas atividades, as quais resolveram sem maiores dificuldades.

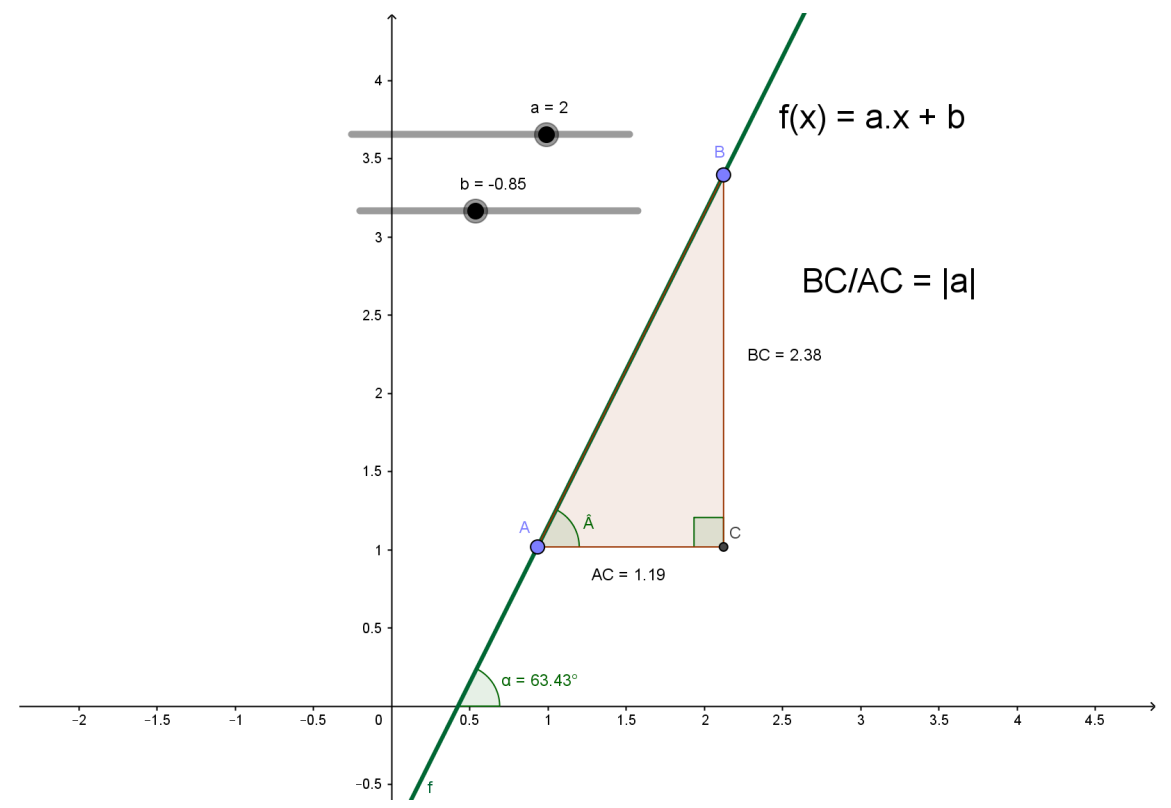

Figura 3. Reta dinâmica e função afim.

No decorrer da atividade de construção do conceito de taxa de variação e identificação do parâmetro a, pode-se perceber que os alunos sentiram-se parte atuante na construção dos conhecimentos matemáticos envolvidos, visto que, participaram, opinaram e contribuíram com saberes anteriormente construídos.

Pode-se perceber que durante a oficina 2 os alunos puderam desenvolver técnicas para o esboço de gráficos das funções afins, oportunizadas pelo uso do software, pois este permitiu que visualizassem de forma dinâmica as mudanças ocasionadas no gráfico quando alteramos seus parâmetros. O GeoGebra também permitiu estabelecer de forma clara a definição de taxa de variação, entretanto, deve existir um cuidado para que usando o software o aluno não deixe de realizar operações e pôr em prática técnicas indispensáveis ao desenvolvimento 
Diego Souza da Silva e João Roberto Lazzarin

do seu raciocínio.

\subsection{Oficina 3 - Função Quadrática}

No decorrer dos 3 períodos que se destinaram as atividades da terceira oficina, buscou-se identificar o auxílio trazido pela análise gráfica das funções quadráticas para a metodologia de resolução de problemas. Por meio de construções realizadas com o uso do GeoGebra, tentou-se propiciar aos alunos estabelecerem relações significativas entre os parâmetros da função quadrática e seu gráfico, construindo um suporte para a resolução de problemas modelados por este tipo de função.

Inicialmente, foi proposto aos alunos o seguinte problema:Com $20 \mathrm{~m}$ de tela deseja-se construir um canil retangular de modo que sua área seja a maior possível. Quais deverão ser as dimensões do canil? Qual será sua área?

Após a leitura e compreensão do problema, os alunos representaram os dados por meio de um desenho, com o qual perceberam que a largura do retângulo varia em função do seu comprimento e a área varia em função das duas dimensões. Dessa forma, decidiram que a melhor maneira de representar a situação proposta era por meio de uma função, devido a dependência entre as variáveis do problema. Com o auxílio do professor, os alunos foram capazes de conjecturar a largura do retângulo em função de seu comprimento, representando o comprimento do retângulo por $x$ e a largura por $(10-x)$. Posteriormente representaram a área $(A)$ do retângulo em função de seu comprimento e de sua largura, chegando a expressão $A=x \cdot(10-x)$, na qual $A$ é a variável dependente $y$. Pela distributividade da multiplicação em relação a subtração escreveram a função $y=-x^{2}-10 x$.

Voltando novamente à leitura do problema, os alunos lembraram que deveriam encontrar o valor de $x$ para o qual $y$ tem seu valor máximo. Mostrando recordar das atividades desenvolvidas na oficina 1, sobre funções, abriram o GeoGebra, representaram a função graficamente e observaram o ponto de máximo do gráfico expressando suas respostas para o problema. Durante o retrospecto do problema, pode-se chegar a soluções algébricas para o mesmo, a partir da análise da parábola construída pelos alunos, com a qual definiu-se as coordenadas do vértice de uma parábola: $V=\left(\frac{-b}{2 a},-\frac{\Delta}{4 a}\right)$.

Ao término desta atividade, pode-se notar que os alunos conseguiram percorrer as etapas necessárias à resolução de problemas, mostrando-se atuantes na elaboração de estratégias e na construção da solução do problema dado. O fato de terem resolvido o problema recorrendo ao esboço do gráfico no GeoGebra mostra a autonomia dos estudantes na resolução do problema e a crescente afinidade com o uso do software e a análise gráfica de funções. Cabe também ressaltar a grande valia do problema proposto para a compreensão da função quadrática, pois no decorrer de sua resolução pode-se estabelecer de forma informal definições e construir conceitos inerentes ao estudo desta função.

Percebeu-se que, alguns alunos, muitas vezes são desatentos ao interpretar um problema, o que mostra a necessidade de instigá-los a realizar atividades que possuam como base a interpretação e a análise de dados. É interessante também, que tais atividades levem o aluno a expressão do seu raciocínio, a fim de que o professor possa visualizar as possíveis falhas de interpretação do problema por parte dos alunos, assim como ajudá-los a expressarem-se de forma clara usando termos matemáticos, ampliando seus conhecimentos em linguagem matemática.

Ainda nessa oficina, os estudantes construíram uma parábola dinâmica no GeoGebra a partir dos parâmetros da função $f(x)=a x^{2}+b x+c$, utilizando os controles deslizantes $a, b$ e $c$ do software, como ilustrado na Figura 4. Mudando o valor do parâmetro (ou coeficiente) 
Revista Ciências Exatas e Naturais, Vol.20, nº.1, Jan/Jun, 2018

$a$, perceberam que seu sinal indica o sentido da concavidade da parábola e que quanto maior seu módulo menor a abertura da parábola. Notaram que se $b>0$ a parábola intersecta o eixo $y$ no ramo crescente, caso contrário, no ramo decrescente. Alterando o valor do parâmetro $c$ visualizaram a translação vertical do gráfico e que o ponto de intersecção da parábola com o eixo $y$ tem coordenadas $(0, c)$.

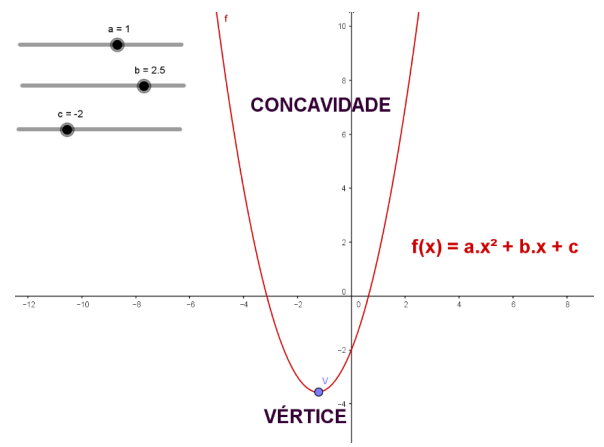

Figura 4. Parábola dinâmica da função $f(x)=x^{2}+b x+c$

De posse das relações estabelecidas anteriormente os alunos resolveram o seguinte problema: Um projétil é lançado de uma plataforma cuja altura é $1 \mathrm{~m}$ do chão, percorrendo uma trajetória parabólica, após 1 segundo, ele está a 3 metros de altura e em 3 segundos está a 1 metro de altura novamente. Considerando que todas estas medidas foram feitas em relação ao chão, responda. Qual a equação que descreve a trajetória do projétil? Qual a altura máxima atingida por este projétil? Em que momento o projétil atingirá o chão?

Para tal, usando o GeoGebra, sobre o plano no qual haviam construído a parábola dinâmica, os alunos plotaram os pontos $(0,1),(1,3)$ e $(3,1)$, dados no problema. Depois, utilizando as relações estabelecidas durante o estudo dos parâmetros da função quadrática, modificaram os valores dos parâmetros $a, b$ e $c$ da parábola dinâmica representativa da função $f(x)=a x^{2}+b x+c$ até que os pontos plotados pertencessem a parábola. Logo, escreveram a função quadrática que modela a situação e responderam aos demais itens usando os métodos que julgaram mais adequados, atendendo ao propósito principal da resolução de problemas que é dar valor às estratégias e a autonomia dos alunos.

Durante a resolução deste problema, pode-se notar que os alunos souberam aproveitar todas as informações trazidas pelo gráfico da função e pelo software que utilizaram para desenhá-lo, analisando o gráfico e os dados calculados pelo GeoGebra. Ainda que, inicialmente, os aprendizes não tenham resolvido as questões usando um sistema de equações, as fórmulas das coordenadas do vértice e o cálculo das raízes da equação do $2^{\circ}$ grau, estes puderam a partir de suas resoluções iniciais ser impulsionados para tal.

\subsection{Oficina 4 - Função Exponencial e Função Logarítmica}

Na última oficina, durante 3 períodos, por meio da resolução de problemas, buscou-se proporcionar aos alunos conjecturar um exemplo de função de tipo exponencial e posteriormente conjecturar sua função inversa, oportunizando-os assim, construírem as definições de função exponencial e de função logarítmica. Desta forma, os alunos foram convidados a resolver o seguinte problema: Em uma cultura de bactérias, a população dobra a cada 
Diego Souza da Silva e João Roberto Lazzarin

hora. Se há 100 bactérias no início da pesquisa, calcule quantas bactérias existirão depois de horas?

Para chegar à solução do problema, os alunos calcularam a quantidade de bactérias presentes na cultura para 1, 2, 3 e 4 horas, sucessivamente. Desta forma, puderam observar a relação entre o número de horas e a quantidade de fatores iguais a 2 no produto que representa o número de bactérias presentes na cultura depois de cada hora. Em vista disto, escreveram as respostas usando potências de base 2 e, consequentemente, a expressão que representa o número de bactérias $y$ depois de horas, determinando assim a função do tipo exponencial, $y=100 \times 2^{x}$, que modela a situação proposta. A partir desta atividade apresentou-se aos alunos a definição de função exponencial dada por [10]: seja $a$ um número real positivo e diferente de 1, chama-se função exponencial de base a, a função $F=R^{+} \rightarrow R$, indicada por $f(x)=a^{x}$.

Para entender melhor a definição anterior e conhecer algumas características da função exponencial, os alunos representaram a exponencial $f(x)=a^{x}$ no GeoGebra a partir de seu parâmetro $a$. Alterando os valores de $a$ e analisando o gráfico, puderam responder a questionamentos que os levaram a entender as restrições feitas ao valor de $a$ e ao contradomínio da função exponencial, compreendendo então, a definição desta função.

Interpretando o gráfico, os alunos notaram que a função é crescente quando $a>1 \mathrm{e}$ decrescente quando $0<a<1$, e que, a imagem da função exponencial corresponde a seu contradomínio fazendo desta uma função sobrejetiva, a qual por sua vez também é injetiva, visto que é estritamente crescente ou estritamente decrescente. Logo, é bijetiva e admite função inversa, neste caso a função logarítmica de base $a$.

Para que os estudantes percebessem a necessidade de definir uma função inversa à função exponencial, lhes foi proposta a questão: Depois de quanto tempo o número de bactérias será igual a 12.800? Entretanto, os alunos resolveram o problema por tentativas até chegar a $2^{7}=12800$, mostrando não lembrar da definição de logaritmo, a qual lhes foi apresentada posteriormente pelo professor.

A partir disto, pode-se pedir que os alunos encontrassem uma expressão matemática do tempo (em horas) em função do número de bactérias, ou seja, determinassem a função inversa de $2^{7}=12800$. Para que os alunos conseguissem chegar ao resultado esperado, estudou-se a definição de função inversa, as técnicas para obtenção da inversa de uma função dada e a leitura gráfica que se pode fazer da simetria, em relação a reta $y=x$, entre uma função e sua inversa.

Como mostra a Figura 5, no GeoGebra, orientados pelo professor, os alunos representaram a função $f(x)=a^{x}$, criaram um ponto $A$ sobre o gráfico de $f$, esboçaram a reta $y=x$ e a função $g(x)=\log _{a} x$. Posteriormente criaram uma reta perpendicular à reta que representa a função identidade e passa por um ponto $A$. Utilizando a ferramenta do GeoGebra "reflexão em relação a uma reta", os alunos estabeleceram a reflexão do ponto $A$ em relação a reta $y=x$, criando assim o ponto $A^{\prime}$. Depois, habilitaram o rastro do ponto $A^{\prime}$ e moveram o ponto $A$, a fim de observar que a curva traçada por $A^{\prime}$ corresponde ao gráfico da função logarítmica de base $a$. Estabelecida a definição de função inversa e a função logarítmica como inversa da função exponencial, os estudantes puderam responder à questão proposta sem maiores dificuldades.

Durante a oficina 4 pode-se perceber que os alunos demonstraram mais habilidades ao usar o software GeoGebra, não necessitando de muita ajuda do professor. Também foi possível notar avanços na escrita e na fala dos estudantes ao expressar seu raciocínio, mostrando ter cada vez mais afinidade com termos próprios da matemática. A partir da leitura que se fez do movimento do gráfico da função exponencial no GeoGebra os alunos pude- 
Revista Ciências Exatas e Naturais, Vol.20 , nº.1, Jan/Jun, 2018

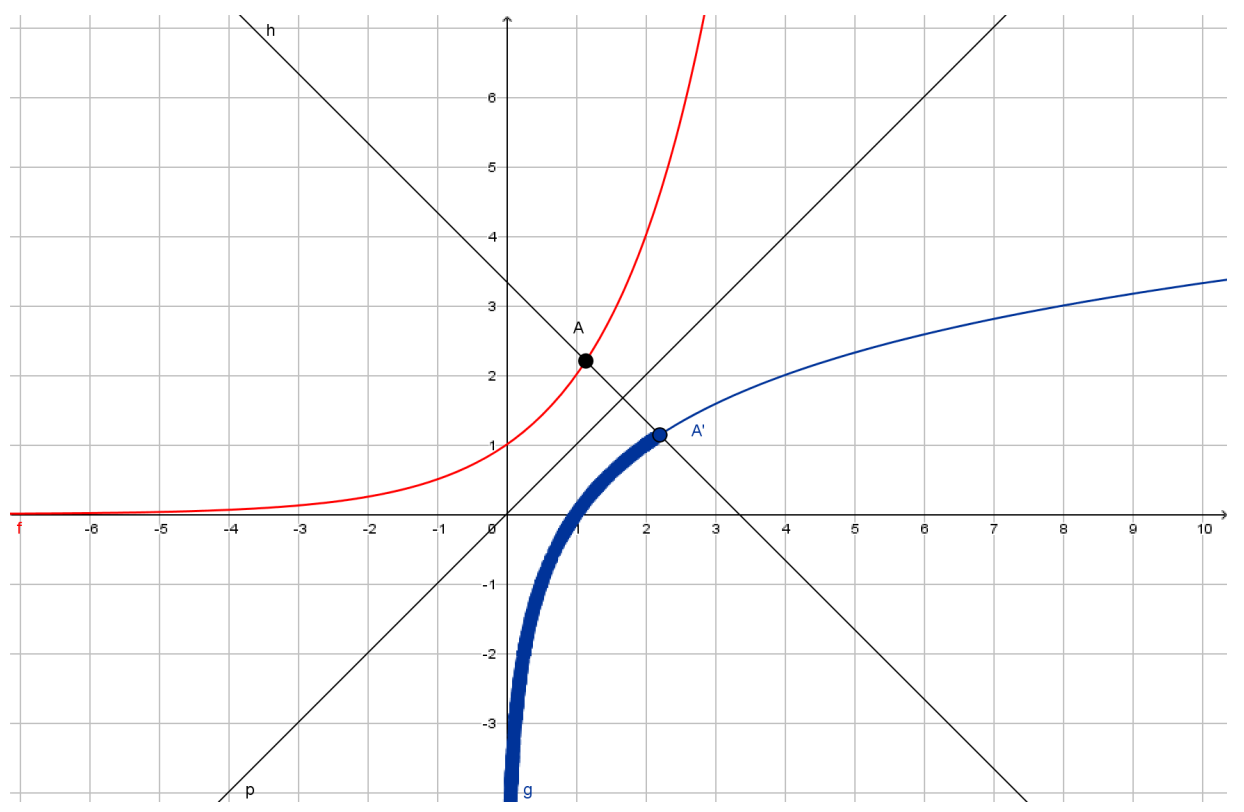

Figura 5. A função $g(x)=\log _{a} x$ como inversa da função $f(x)=a^{x}$

ram compreender características importantes desta função, assim como entender melhor sua definição. Ao definir a função logarítmica como inversa da função exponencial teve-se a oportunidade de construir conceitos inerentes a compreensão de funções inversas. Foi possível notar ainda, a motivação e interesse dos aprendizes durante a atividade de comparação dos gráficos de uma função e sua inversa no GeoGebra.

\section{Conclusões}

Encerradas as etapas da pesquisa e análise, cabe aqui apresentar uma síntese das reflexões acerca do assunto que foi abordado durante uma proposta pedagógica, que fez uso de algumas tendências em educação matemática e enfatizou a interpretação por meio da abordagem visual dada ao tema funções. As percepções do professor e as expressões dos alunos foram devidamente analisadas, isso forneceu subsídios para levantar algumas conclusões apresentadas a seguir.

O ensino da Matemática tem se apresentado como um desafio constante, devido a imensa quantidade de obstáculos que se colocam frente ao processo de ensino-aprendizagem da disciplina. Desafios estes, frequentemente relatados por diversos autores, cujas causas são inúmeras, podendo ser de natureza material, metodológica, cognitiva e social.

Tratando-se do estudo de funções, pode-se perceber inicialmente que a maioria dos alunos apresentava muitas dificuldades relativas à compreensão de símbolos matemáticos e a interpretação, tanto dos problemas que lhes foram propostos, quanto dos gráficos a serem analisados. Outra dificuldade eloquente dos alunos, apresentou-se no momento de escrever corretamente e usar a nomenclatura matemática adequada a cada situação, o que demonstrou a falta de hábito dos estudantes em trabalhar com problemas que os façam expressar suas ideias de forma concatenada e dentro de um padrão lógico aceitável. Cabe ainda res- 
Diego Souza da Silva e João Roberto Lazzarin

saltar que no início da aplicação da sequência didática, os estudantes apresentaram muitas dificuldades para relacionar grandezas e diferentes formas de representação de um mesmo objeto matemático.

Entretanto, houve uma melhora gradativa destas habilidades no decorrer da proposta pedagógica, oportunizada pelas atividades de interpretação e análise gráfica, com o uso do software GeoGebra, que propiciaram o envolvimento dos alunos em discussões e reflexões sobre as diferentes representações de uma função e os induziram a expor seu pensamento e escrevê-lo, oportunizando ao professor visualizar as possíveis falhas de interpretação por parte dos alunos e seus conhecimentos prévios acerca do tema em estudo, e assim, ajudálos a expressarem-se de forma mais adequada usando termos matemáticos, ampliando seus conhecimentos em linguagem matemática.

As maiores contribuições trazidas, pelo uso do GeoGebra, ao processo de ensino-aprendizagem, dentro desta proposta pedagógica, foram o interesse e a motivação dos alunos para explorar os objetos de estudo propostos. Ainda que nos primeiros contatos com o software os alunos tenham tido dificuldades para manuseá-lo, necessitando de constantes intervenções do professor, isto não foi um empecilho para que o usassem ao analisar e interpretar as funções graficamente.

O GeoGebra serviu também como uma importante ferramenta para a construção de conceitos e compressão de características das funções abordadas, principalmente, as possíveis mudanças ocasionadas no gráfico de uma função quando alteramos seus parâmetros, comparando assim funções pertencentes a uma mesma família e estabelecendo relações entre as expressões analíticas das funções e os gráficos que as representam. Além disso, o software serviu como um recurso na resolução de problemas, em alguns momentos como calculadora gráfica, em outros, oferecendo um rápido auxílio visual para levantar hipóteses, verificá-las e construir conjecturas, favorecendo a autonomia dos estudantes na construção dos conhecimentos matemáticos.

A Resolução de Problemas e a Modelagem Matemática fizeram-se adequadas aos propósitos da pesquisa, pois a nosso ver, o estudo deste tema só tem sentido quando destinado a modelar e resolver problemas em situações reais. Entende-se que estas tendências em educação matemática, aliadas a utilização do GeoGebra, podem ocorrer conjuntamente, visto que o GeoGebra tem grande potencial interativo e de animação ao tratar de conceitos referentes a funções e suas características, o que oportuniza maiores chances de aprendizagem.

Ao se enfatizar a análise e expressão gráfica durante a etapa inicial do estudo das funções, pode-se mostrar aos alunos que a matemática não é uma ciência isolada, pois estes sistemas representativos são usados com frequência para comunicação em outras áreas do conhecimento. Através da análise gráfica os alunos puderam compreender o conceito de função e outros conceitos subjacentes a ele, utilizando como exemplos várias relações que expressam, ou não, funções, sem ater-se a suas particularidades e a simbologia presente nas expressões analíticas destas relações.

Já num segundo momento, as atividades de exploração dos gráficos de funções, oportunizaram aos estudantes: visualizar por conta própria características importantes de cada uma das funções estudadas; atribuir significado às definições formais de cada tipo de função e a terminologia utilizada em cada caso; estabelecer relações e transitar entre diferentes registros desse objeto matemático; compreender as relações de dependência entre as grandezas envolvidas numa determinada situação; construir conceitos e habilidades importantes à compreensão de fenômenos modelados por funções e analisar as diferenças e semelhanças entre problemas propostos, a fim de serem capazes de adaptar os conhecimentos construídos a novas situações problema. 
Revista Ciências Exatas e Naturais, Vol.20 , nº.1, Jan/Jun, 2018

Além disso, pode-se concluir que a abordagem visual se faz mais atrativa aos alunos do que a simples exposição formal de definições, servindo de facilitadora do processo de ensino, assim como do processo de compreensão e construção de conceitos por parte dos alunos, fazendo dos estudantes sujeitos autônomos no processo de aprendizagem e do professor um mediador e facilitador deste processo, ao escolher as atividades e intervir quando necessário para a construção de novos saberes.

Portanto, aliar a abordagem gráfica de funções a situações que mostrem ao aluno a importância e aplicabilidade do conteúdo, dentro e fora da escola, é essencial para que haja a motivação, e por consequência a construção dos conhecimentos em funções matemáticas pelos alunos.

\section{Referências}

[1] CHEVALLARD, Yves; BOSCH, Marianna; GASCÓN, Josep. Estudar Matemáticas: o elo perdido entre o ensino e a aprendizagem. Tradução de Daisy Vaz de Moraes. Porto Alegre: Artmed, 2001.87p. 1999.

[2] ALBÉ, Maristela de Quadros; FILIPPSEN, Rosane Maria Jardim. Função trigonométrica: um enfoque aplicado ao ensino técnico. Revista Liberato. Novo Hamburgo, ano 7 , n. 8, p. 12-23, out. 2006.

[3] CARNEIRO, Vera Clotilde. Funções Elementares: 100 situações-problema de matemática. Porto Alegre: UFRGS, 1993.

[4] INEP, Inep apresenta resultados do Saeb/Prova Brasil 2015. Brasília: INEP/MEC, 2016. Disponível em: <http://portal.inep.gov.br/artigo//asset_publisher/B4AQV9zFY7Bv/content/inep-apresenta-resultados-do-saeb-provabrasil-2015/21206>. Acesso em: 08 mai. 2017.

[5] BRASIL. Orientações Curriculares para o Ensino Médio: Ciências da Natureza, Matemática e suas Tecnologias. Brasília: Ministério da Educação, Secretaria de Educação Básica, 2008. v. 2.

[6] BASSANEZI, Rodney Carlos. Ensino-Aprendizagem com Modelagem Matemática: uma nova estratégia. São Paulo: Contexto, 2002.

[7] DANTE, Luiz Roberto. Formulação e Resolução de problemas de matemática: Teoria e Prática. São Paulo: Ática, 2010.

[8] POLYA, George. A arte de resolver problemas: um novo aspecto do método matemático. 2.ed. Rio de Janeiro: Interciência, 1995.

[9] BRASIL. Secretaria de Educação Média e Tecnológica do Ministério da Educação. Parâmetros Curriculares Nacionais para o Ensino Médio. Brasília: SEMT/MEC. 1999.

[10] LIMA, Elon Lages. Números e Funções Reais. Coleção PROFMAT. 1. ed. Rio de Janeiro: SBM, 2013. 